\title{
The Operation of School Lunches in Japan: Construction of a System Considering Sustainability
}

\author{
Satomi Maruyama*1 and Aoi Kurokawa*2 \\ *1 Department of Food and Nutritional Environment, College of Human Life and Environment, Kinjo Gakuin University \\ ${ }^{*}$ Department of Nutritional Science, Faculty of Health and Welfare Science, Nayoro City University
}

doi:10.5264/eiyogakuzashi.76.S12

\begin{abstract}
Objective: This study aimed to outline the operation of the Japanese school lunch system with reference to the cooking delivery system, operation organization, finances, and management resources, in addition to discussing the development of a sustainable school lunch system.

Method: Laws and public notices, and general statistical surveys of the relevant government bodies and municipalities published on the Internet have been cited to enable foreign countries to utilize the discussed contents in the implementation of such programs in their country.

Results: Japanese school lunches are systematized and operated under the guidance of the Board of Education of the Prefecture or designated city and the Board of Education of the municipality based on the laws established by the Ministry of Education, Culture, Sports, Science and Technology. The operation system has been developed to ensure continuous safety management to avoid health hazards owing to school lunch consumption.

Conclusions: The School Lunch Act and many other laws and regulations related to the school lunch enabled the establishment of a sustainable system for the provision of school lunch in Japan. Japan employs a cooking delivery system in which designated personnel decide and establish an organized system according to specific guidelines. These factors helped construct this sustainable system.
\end{abstract}

Jpn. J. Nutr. Diet., Vol.76 Supplement 1 S12-S22（2018）

Key words: operation system, cooking and delivery system, operating organizations, finance, management resources

\section{Introduction}

School lunches in Japan started in 1889, with the provision of free food for poor children. Such programs have operating for approximately 130 years. In 1946, school meals were offered to every child and it spread to the entire country in 1947, after World War II. In 1954, the School Lunch Act was enacted, and today's school lunch program was established ${ }^{1}$.

In 2015 , the implementation rate of school lunches was 99.1\% in Elementary Schools and 88.1\% in Junior High Schools. School lunches are provided to $10,024,943$ children and students ${ }^{2)}$, and they have contributed to the improvement of the physical status of the beneficiaries during the era of food shortage after the war. Today, it contributes to the healthy physical and mental develop- ment of children in their growth period, in addition to developing an accurate understanding and appropriate judgment skills about food. The operation method of school lunches has changed in accordance to the health and social problems in each era. Currently, school lunches are provided as a part of a sustainable system.

This chapter aims to outline the sustainable school lunch operation system of Japanese school lunches from the perspective of the cooking delivery system, operation organization, finances, and management resources, in addition to discussing about the implementation of a sustainable school lunch system.

\section{Methods}

This chapter outlines the overall operation system of

Corresponding Author: Satomi Maruyama. Department of Food and Nutritional Environment, College of Human Life and Environment, Kinjo Gakuin University, 2-1723, Oomori, Moriyama-ku, Nagoya-city, Aichi 463-8521 Japan Tel: +81-52-798-0180 Fax: +81-52-798-0370 E-mail: maruyama@kinjo-u.ac.jp 
school lunches in Japan, including the cooking and delivery system of school lunches, the operation organization of school lunches, finances, and management resources. In this paper, food delivery is defined as the process of transporting lunch, and serving is defined as the task of dishing up food on a plate. Lastly, the system of serving food and the tableware used have been discussed. The laws and public notices, as well as general statistical surveys of the relevant government and municipalities published on the Internet have been cited to make it possible for foreign countries to utilize the discussed contents in the implementation of such programs in their country. The web addresses of the referenced websites have been provided in the reference section.

The referred operating organizations were limited to those from prefectures that published the "school lunch guide" and "school lunch operation and guidance" on the Internet, and those which had appointed more than 100 Diet and Nutrition Teachers to oversee the overall work in the school lunch organization.

\section{Results}

Japanese school lunches are systematized and operated under the organization of the Board of Education of the Prefecture or designated city and the Board of Education of the municipality based on the laws established by the Ministry of Education, Culture, Sports, Science and Technology (MEXT). The operation system ensures the complete dissemination of school lunches while achieving the following goals of school lunches clearly stipulated in the School Lunch Act: (1)To maintain and promote children's health through the ingestion of adequate nutrition; (2) To deepen children's correct understanding of meals in daily life, and to enhance judgment that empowers them to build healthy and desirable eating habits. The operation system also ensures continuous safety management to avoid health hazards owing to school lunch consumption.

The implementing entity of the operation system is each municipality, which employs the school personnel responsible for the operation of the school lunch program.

\section{Cooking and delivery system}

There are two representative systems in the cooking and delivery system for operating the school lunch program in Japan: The conventional system and commissary system.

In the conventional system, the school kitchen is located in the school. The food is cooked and delivered at the same facility. In the commissary system, a school kitchen jointly purchases and stores ingredients, and delivers school lunches to several schools. There is also a parent-child system of school lunches, in which a school with a kitchen also transports school lunches to nearby schools.

School establishment personnel review sustainable cooking methods according to the school demographics and financial resources. Therefore, sometimes both systems are adopted in some areas, instead of operating with a single system alone.

One example is listed below, although the scale of the number of meals of the conventional system and the commissary system varies depending on the region. In City $\mathrm{A}^{3)}$, which adopts two systems, about 34,500 meals are provided through the conventional system (minimum of 88 meals and maximum of 460 meals/school kitchen), and about 44,000 meals are provided through the commissary system (for 103 schools, 8,000 9,500 meals/5 collective kitchens). Moreover, City $\mathrm{B}^{4)}$, which adopts only the commissary system, provides 21,000 meals per day to 51 schools by cooking them at a collective kitchen.

Another cooking delivering system is the delivery system, in which a private contractor distributes school lunches cooked at a business facility. An overview of these systems has been presented in Table $1^{5,6)}$.

Table 2 shows the trends in the number of schools by the cooking system employed, from 2006 to 2014 ${ }^{7}$. The numbers of schools using the commissary system was the largest, followed by the conventional system and the other cooking systems. The proportion of the conventional system was about $43 \%$ during 2006 to 2014 , and that of the commissary system was $54.6 \%$ in $2006,55.0 \%$ in 2012 , and $54.5 \%$ in 2014 . The proportion of other cooking systems has been increasing each year, from $1.6 \%$ in 2006 to $3.0 \%$ in 2014. The number of schools in Japan has been decreasing $^{8)}$. Therefore, collective kitchens are often combined. For instance, a new collective kitchen that was planned to have two kitchens that would each prepare 6,000 meals ended up combining them into a collective kitchen that can prepare 12,000 meals, to achieve cost reduction and to account for a decrease in the number of school pupils ${ }^{9)}$. 


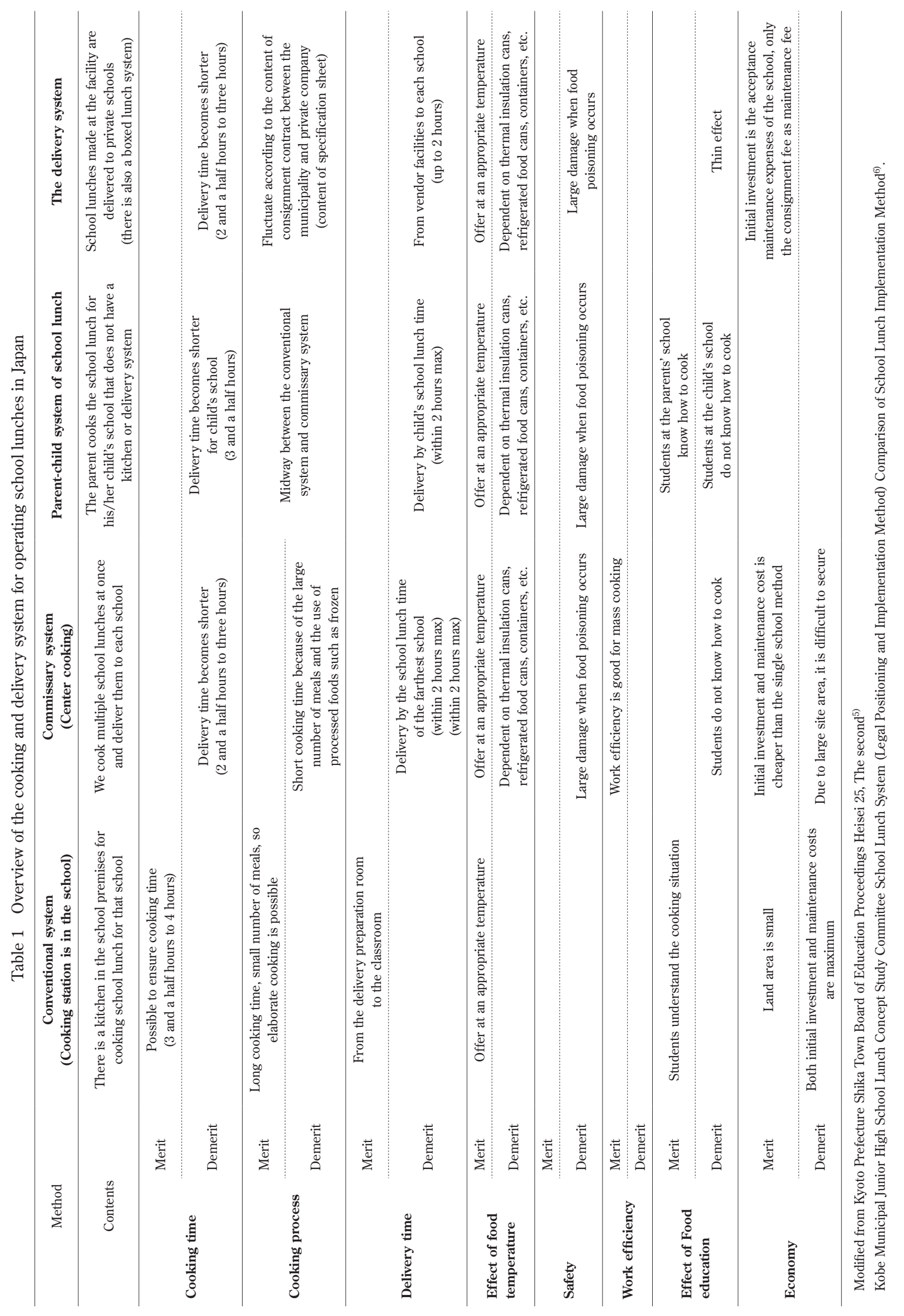


Table 2 The trends in the number of schools by cooking systems from 2006 to 2014

\begin{tabular}{ccccccc}
\hline & $\begin{array}{c}\text { The conventional system } \\
\text { Number of } \\
\text { schools } \\
\text { (school) }\end{array}$ & Ratio (\%) & $\begin{array}{c}\text { The commissary system } \\
\text { Number of } \\
\text { schools } \\
\text { (school) }\end{array}$ & Ratio (\%) & $\begin{array}{c}\text { Other cooking systems } \\
\text { Number of } \\
\text { schools } \\
\text { (school) }\end{array}$ & Ratio (\%) \\
\hline 2006 & 13,137 & 43.8 & 16,345 & 54.6 & 480 & 1.6 \\
2007 & 13,013 & 43.6 & 16,313 & 54.7 & 516 & 1.7 \\
2008 & 12,856 & 43.4 & 16,237 & 54.8 & 541 & 1.8 \\
2009 & - & - & - & - & - & - \\
2010 & 12,615 & 43.1 & 16,026 & 54.8 & 614 & 2.1 \\
2011 & - & - & - & - & - & - \\
2012 & 12,264 & 42.6 & 15,838 & 55.0 & 674 & 2.3 \\
2013 & - & - & - & - & - & - \\
2014 & 12,091 & 42.4 & 15,542 & 54.5 & 869 & 3.0 \\
\hline
\end{tabular}

- No data due to unexplored data.

General Window of Government Statistics Survey on School Lunch Implementation Status ${ }^{7}$.

The survey on the cooking systems is conducted every two years from 2009.

Thus, such social factors may mitigate the increase in the number of kitchens.

According to the School Lunch Act, since 2009, school lunches are considered to "fulfill a significant role in cultivating accurate an understanding and judgment skills about food." The national government also urges each municipality to not only enrich the contents of the meal but to also ensure the thorough prevention of food poisoning and food allergy accidents. Each municipality responded to the request of the national government by rebuilding and remodeling its kitchen, or changing to a cooking station system that can correspond to the Standards of Hygiene Control of School Lunches and guidelines for addressing food allergies in school lunch services. In City $\mathrm{C}$, which switched from a delivery system to a parent-child system for the school lunch to further enhance allergy management, verified its improvement and scheduled all junior high schools to switch to a parentchild system ${ }^{10)}$. Owing to the increasing need for changes such as allergy management, other systems, such as the proximity school compatible kitchen system, are increasing.

\section{Operating organizations of school lunches}

Figure 1 shows an example of a single school in a school lunch operation organization with reference to the roles of the school personnel. Figure 2 shows an example of the organization of a collective kitchen ${ }^{11 \sim 15)}$. In the case of a single school, the Board of Education communicates with the school and the kitchen located in the school, and provides guidance and advice on hygiene management and about the food provided at the school. Additionally, it provides training for related faculty and staff, and develops menus and purchases foods. In the case of a collective kitchen, Diet and Nutrition Teachers and the kitchen cooperates with each other and receives guidance and advice from the Board of Education. The operation organization of school lunches includes the principal, Diet and Nutrition Teachers, teachers, parents and guardians, and other stakeholders. The principal becomes the chief of the school's planning and operations, and he/she supervises the staff involved. The school lunch committee, school lunch menu planning committee, material selection committee, supplier selection committee, and other committees prepare a suitable menu that takes nutritional balance and hygiene management into account, and organizes a purchasing system that ensures food safety. In the case of a collective kitchen, a collective kitchen management committee is added to these operating committees.

The operation of the school lunch depends on the size of the school and the cooking system adopted. Thus, the operation organization of the school lunch program is a collaborative organization that can cooperate with faculty and staff related to the school, parents and guardians, and the community, although it depends on the actual size of the school, staff organization, facility equipment, and the local community.

Each Prefectural Board of Education prepares a school lunch guide and establishes school lunch operation guide- 


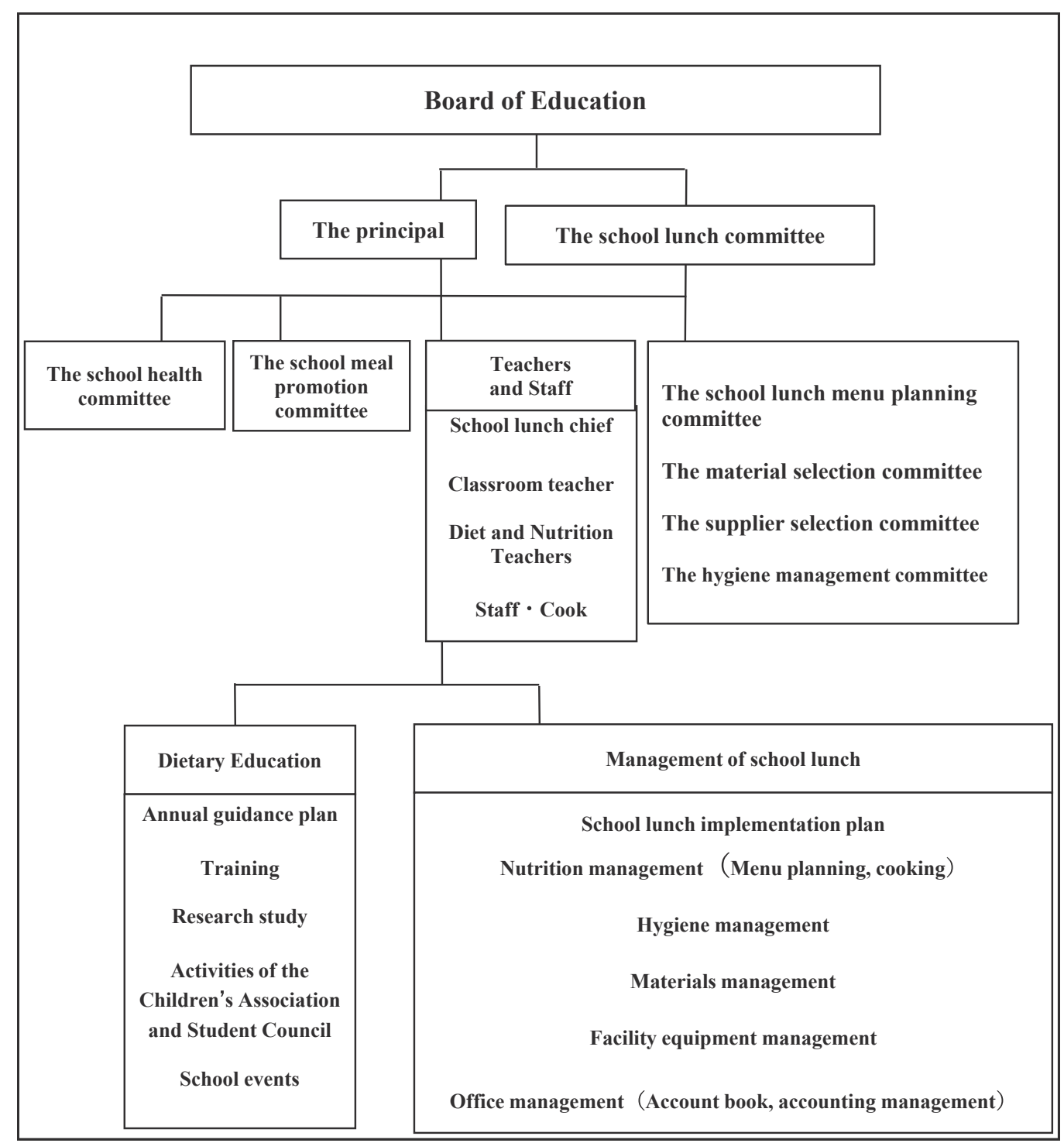

Figure 1 Operating organizations of school lunches (single school)

Partial modification of Nagano Prefecture Board of Education School Lunch Instruction Manual Operation Management Section 1, School Lunch Operation I School Lunch Operation Organization example ${ }^{11,16)}$.

lines, which are followed by the operation organization. Many municipalities have published their "school lunch guide" and "school lunch operation guidelines" on the Internet, as a manual ${ }^{11 \sim 16)}$.

\section{Finance and management resources for school} lunch operation

1) Budgeting of management resources

As shown in Table 3, the operating expenses for school lunches include (1) labor costs, (2) ingredient costs, (3) facility equipment, and (4) other costs, including utilities. According to the beneficiary payment principle, the cost allocation of the school lunch management resources of Japan $^{17)}$, parents of students who are beneficiaries of the program bear only the ingredient cost as the meal fee ${ }^{18)}$.
However, the school establishment personnel can also offer assistance. Moreover, the national government can supplement some of the expenses. Public expenditure, which the school establishment personnel bears, includes the operating expenses needed to provide school lunch, such as facility equipment cost and labor cost, in addition to other costs, such as utilities. A part of the expenses may be borne by the national government. The latter tends to choose a cost-effective system in terms finance, as costs other than ingredient costs must be borne by the national government and municipalities. The disadvantage of a school kitchen and a collective kitchen is that the initial investment and maintenance cost is large, as shown in Table 1. As shown in Table 2, while the number of total 


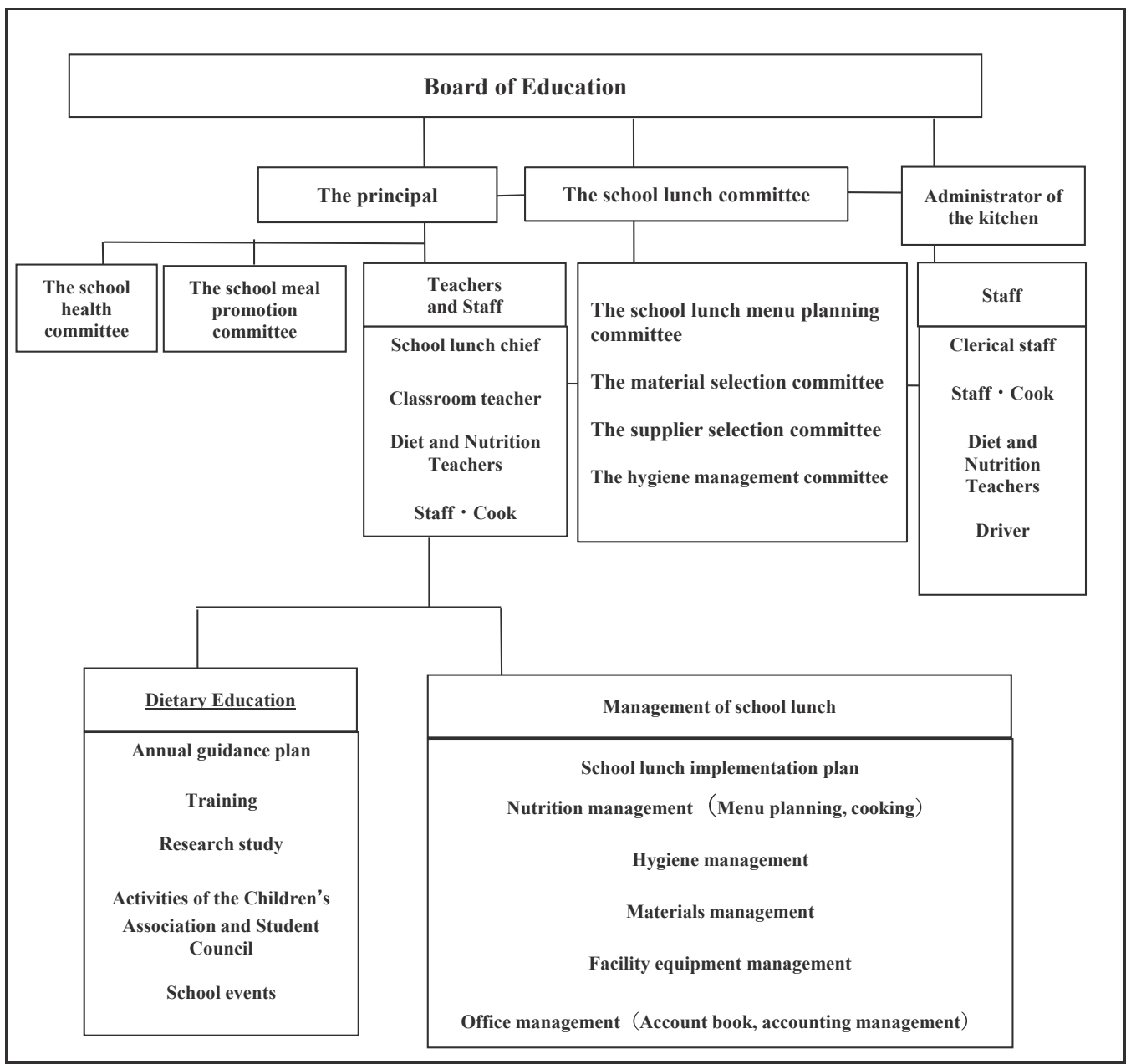

Figure 2 Operating organizations of school lunches (joint-cooking station)

Partial modification of Nagano Prefecture Board of Education School Lunch Instruction Manual Operation Management Section 1, School Lunch Operation I School Lunch Operation Organization example ${ }^{11,16)}$.

Table 3 A break down of the operating expenses for school lunches in Japan

\begin{tabular}{|c|c|}
\hline A break down of the cost of resources & Costs \\
\hline (1) Labor costs & $\begin{array}{l}\text { Municipal tax (Public expenses); office workers, etc. } \\
\text { Prefectural tax (Public expenses); diet and nutrition school } \\
\text { teachers } \cdot \text { school dietitian }\end{array}$ \\
\hline (2) Ingredient costs & Parents (Beneficiary) \\
\hline $\begin{array}{l}\text { (3) Facility equipment costs } \\
\text { (facility equipment and tableware) }\end{array}$ & National government and municipality (Public expenses) \\
\hline (4) Other costs (Photothermal water costs, etc.) & Municipal tax (Public expenses) \\
\hline
\end{tabular}

schools has decreased, the number of other cooking systems is increasing. This may be related to the large financial burden of a school kitchen or a collective kitchen.

One of the cost-effective methods is outsourcing school lunches to the private sector. In this regard, in 2006, 6,422 public schools, which combine elementary and junior high schools, were found outsource school lunch services to the private sector, with an outsourcing rate of $21.3 \%$. However, these figures increased to 11,822 schools with an outsourcing rate of $41.3 \%$ in $2014^{19)}$. The number of schools that outsource cooking work, dishwashing, and boiler management is increasing each year. It is thought that the efficiency of operation and maintenance can be improved by outsourcing work requiring standardized tasks and expert knowledge. Additionally, the outsourcing of goods purchase management is increasing each year in the commissary system, possibly because, compared to school kitchens, it is easier for collective kitchens to out- 
Table 4 The trends of the number of school lunch nutritionist, Diet and Nutrition Teacher, and school lunch cooks

\begin{tabular}{cccccccc}
\hline & \multicolumn{3}{c}{ Full-time school lunch cooks } & Part-time school lunch cooks & Total \\
& $\begin{array}{c}\text { School lunch } \\
\text { nutritionist } \\
\text { (Number) }\end{array}$ & $\begin{array}{c}\text { Diet and } \\
\text { Nutiriton } \\
\text { Teacher } \\
\text { (Number) }\end{array}$ & $\begin{array}{c}\text { Staff } \\
\text { (Number) }\end{array}$ & Ratio (\%) & $\begin{array}{c}\text { Staff } \\
\text { (Number) }\end{array}$ & Ratio (\%) & (Number) \\
\hline 2005 & 12,221 & 16 & 46,102 & 66.3 & 23,476 & 33.7 & 69,578 \\
2006 & 12,305 & 316 & 44,414 & 65.0 & 23,867 & 35.0 & 68,281 \\
2007 & 12,318 & 1,016 & 42,904 & 64.3 & 23,855 & 35.7 & 66,759 \\
2008 & 12,247 & 1,967 & 40,145 & 62.5 & 24,105 & 37.5 & 64,250 \\
2009 & 12,325 & 2,736 & 38,046 & 61.1 & 24,228 & 38.9 & 62,274 \\
2010 & 12,199 & 3,476 & 36,645 & 59.7 & 24,711 & 40.3 & 61,356 \\
2011 & 11,497 & 3,743 & 33,807 & 59.9 & 22,588 & 40.1 & 56,395 \\
2012 & 12,096 & 4,355 & 34,081 & 58.1 & 24,609 & 41.9 & 58,690 \\
2013 & 12,143 & 4,703 & 32,073 & 57.2 & 24,047 & 42.8 & 56,120 \\
2014 & 12,033 & 5,064 & 31,478 & 57.1 & 23,694 & 42.9 & 55,172 \\
\hline
\end{tabular}

$\dagger$ Total number of Diet and Nutrition Teachers and school dietitians.

Ministry of Education, Culture, Sports, Science and Technology, Japan: The Results of School Lunch Implementation Survey. Lunch Implementation Status ${ }^{7}$.

source the purchase of goods owing to the large number of meals the latter provide. Thus, it is easier to outsource the large quantity purchases to a standardized purchase system. Outsourcing of food ingredient has been increasing in recent years and is expected to continue, regarding purchase management of food ingredients.

In a discussion in the House of Representatives, it was explained that the conventional system has the disadvantage of having a large financial burden, such as facility equipment cost and labor costs, whereas the commissary system has an advantage of having a small burden in these $\operatorname{areas}^{20)}$. This discussion indicates the need to switch to a commissary system during remodeling, because it is expensive for existing school kitchens to provide equipment that adheres to standards, in addition to the large financial burden in school kitchens due to the required individual investment on facility equipment.

2) Management resources

(1) Labor

Table 4 shows the trends in the employment of Diet and Nutrition Teachers, school dietitians, and school lunch cooks, who are the labor for Japanese school lunches ${ }^{7)}$. The number of Diet and Nutrition Teachers has continued to increase since the system of nutritional teachers started in 2005.

There is no change in the total number of Diet and Nutrition Teachers and school dietitians; however, the proportion of the Diet and Nutrition Teachers has increased while the number of school lunch cooks has decreased. Additionally, with the decrease in the proportion of full-time school lunch cooks, that of part-time cooks has increased.

(2) Ingredients

The proportion of the number of local products increased from $23.3 \%$ in 2007 to $25.8 \%$ in 2013. Moreover, the proportion of domestic ingredients increased slightly from $76.8 \%$ in 2012 when the survey started, to $77.1 \%$ in $2013^{21)}$. Ministry of Education, Culture, Sports, Science and Technology requires that the school lunch program be utilized as an educational medium while implementing it organizationally and systematically through Diet and Nutrition Teachers, school dietitians, and all faculty members $^{22)}$. The ingredients are used to meet this requirement.

(3) Facility equipment

School lunches must be provided hygienically. Therefore, the meal facilities are operated hygienically based on the guidelines of Hazard Analysis and Critical Control Point (HACCP) The conditions changed after the amendment of the Standards of Hygiene Control of School Lunches in 2009, as described below ${ }^{23)}$.

- The school lunch facility is divided into three zones, "contaminated work zone," "non-contaminated work zone," and "other zone."

- The environment of the kitchen strives to make it a kitchen that introduces a dry system that keeps the 


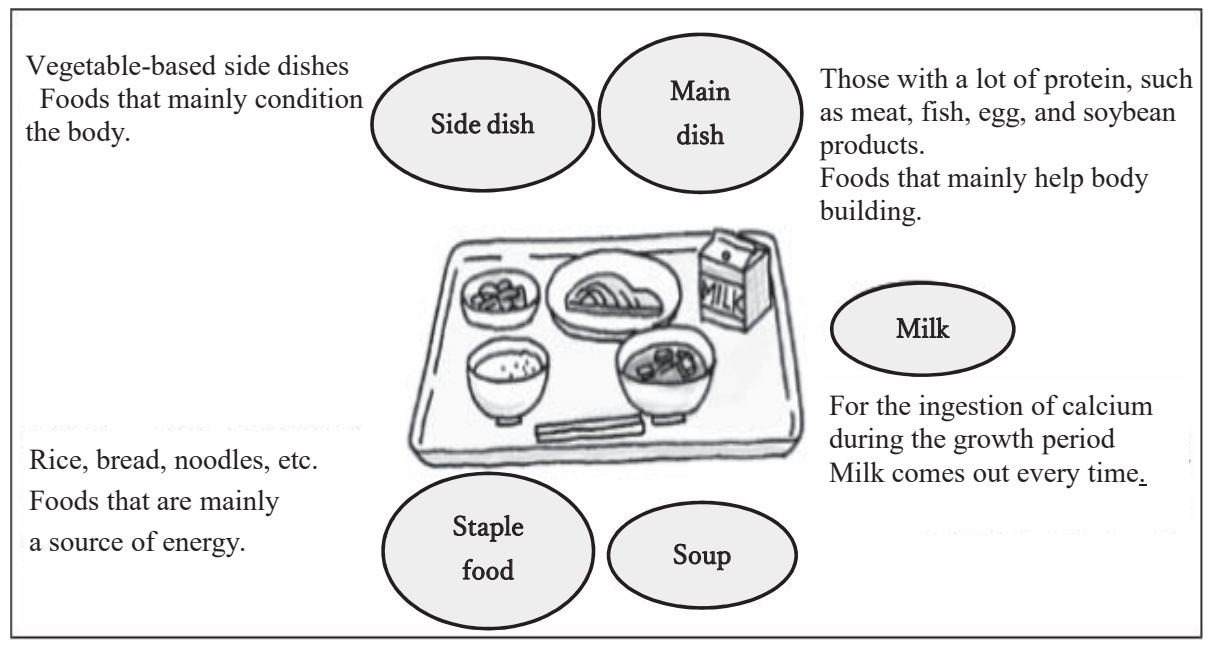

Figure 3 How to arrange tableware accurately

Students arrange the staple food, main dish, and side dishes in the correct position and eat lunch. How to accurately arrange tableware ${ }^{22)}$.

floor dry. Also, in case of a wet system which can be used by wetting the floor, "to dry operation to maintain floor drying".

- As for the toilet room dedicated to school lunch workers, efforts are made to provide a designated "place to wear cooking clothes in front of the private room or the toilet."

- As for sinks in the "precooking room," a three-tank type structure that separates the sinks used for washing food for cooking, food for non-cooking, and appliances is required. Furthermore, as for the "cooking room," it must install a washing sink for food and utensils, which should not be shared.

- Refrigerators and freezing equipment "for ingredients and cooked food" must to be provided.

- As for special hand washing facilities for school lunch employees, the school lunch facility must install sinks "in the antechamber and private room of the toilet."

- Additionally, the faucets of special hand washing facilities of the school lunch workers must provide "hot water."

\section{Serving}

\section{1) Serving system}

There are two types of serving systems, one in which the eater performs all the serving and cleaning up, and another in which the school lunch provider performs all of the serving and cleaning. Additionally, an intermediate system that combines these two systems may be implemented. For school lunches in Japan, pupils on school lunch duty are selected to perform the work of serving the school lunches to other pupils. The clothing and sanitary guidelines are decided based on the student guidance rules of the school, and school pupils on school lunch duty are placed in each class by the municipality's school lunch operation rules, to have them cooperate in serving.

\section{2) Tableware}

Ministry of Education, Culture, Sports, Science and Technology publishes guidelines for the appropriate arrangement of tableware in school lunches. Specifically, it mentions, "I will arrange the staple food, main dish, and side dishes correctly and eat" And explains the same with illustrations, as shown in Figure $3^{24)}$. In addition to combining multiple tableware such as rice bowl, soup bowl, main dish, and a side dish, as shown in Figure 3, it is also possible to use a pallet, which is a single plate divided into compartments. Table 5 presents data on the usage of tableware and utensils in public elementary and junior high schools. The ratio of using three pieces of tableware was the highest, with 17,350 schools (57.6\%) using the same. Chopsticks, spoons, forks, and sporks were used as utensils. Specifically, 29,857 (99.1\%) public elementary and junior high schools used chopsticks, which is a traditional Japanese utensil ${ }^{25)}$.

\section{Considerations}

The school-lunch system needs to be managed thoroughly in a sustainable manner in terms of safety control, 
Table 5 The usage of tableware and utensils for public elementary and junior high schools

Number of schools (\%)

\begin{tabular}{rccccccc}
\hline \multicolumn{4}{c}{ Number of uses of tableware } & \multicolumn{4}{c}{ Utensils } \\
& 3 & 2 & 4 & Chopsticks & Spoons & Forks & Sporks \\
\hline 2003 & $13,044(42.5)$ & $4,750(15.5)$ & $5,253(17.1)$ & $30,061(97.9)$ & $19,135(62.3)$ & $10,190(33.2)$ & $10,234(33.3)$ \\
2006 & $17,350(57.6)$ & $5,313(17.6)$ & $3,156(10.5)$ & $29,857(99.1)$ & $20,800(69.0)$ & $10,130(33.6)$ & $8,374(27.8)$ \\
\hline
\end{tabular}

The subjects of the survey are public elementary schools and junior high schools that provide full meals or supplementary meals. Number of surveyed schools in 2003: 30,719 schools, number of survey schools in 2006: 30,057 (by back calculation from proportion). Ministry of Education, Culture, Sports, Science and Technology: Survey on Cafeteria/Eating Utensils Usage in School Lunch (as of May 1, 2006) Summary of the Survey Results: 4 Study on Dining Room/Meal Eqipment Usage Situation in School Lunch (as of May 1, 2006. Previous Survey 2013) ${ }^{24)}$.

to protect children from health hazards from eating school lunch. The School Lunch Act has played a great role in maintaining and improving the safety level of the system.

A solid fiscal base is required to establish a system for safe food preparation and catering. In addition, there should be an operating system for resource management. Hence, the government developed both an efficient system and methodology, and established laws accordingly. Laws were established not only for creating a solid fiscal base but also for determining the roles of the central and local governments in the implementation of the school lunch program. The school lunch system of the Japan that the central and local governments operated was able to establish a sustainable system through a number of relevant laws and regulations, including the School Lunch Act.

\section{Conclusions}

This study aimed to discuss the sustainable operation system of school lunches in Japan, which are eaten by most school aged children. The implementation rate for this program in Japan is $99.1 \%$ in elementary schools and $88.1 \%$ in junior high schools, and the school lunch is provided to $10,024,943$ school pupils nationwide. The operation system has been developed and improved over about 70 years, to create a system that would absolutely and continuously ensure safety management to avoid health hazards owing to school lunch consumption. A personnel from the school establishment, who is responsible to oversee the operation system, makes decisions on the cooking serving system based on the policies of the establishment personnel and restrictions of the financial and management resources. He/she takes the initiative and organizes the school lunch operation organization. The system is operated by the cited school lunch guidelines and manuals. The costs for operating school lunches in Japan are borne by public expenditure, which includes labor cost, facility equipment cost, utilities, and other expenses. Additionally, parents and guardians bear the ingredient cost. Diet and Nutrition Teachers, school dietitians, and school lunch cooks, who comprise the labor who operate the school lunch program, are responsible for the daily working of the system.

These factors help construct a sustainable system. Future issues include the decrease in the number of school pupils who eat school lunches due to Japan's population decrease, in addition to the outsourcing of processes to private contractors to streamline the operation and maintenance of the system, and to decrease the public burden of labor cost and facility equipment cost.

\section{Conflict of Interest}

There are no conflicts of interest to declare.

\section{References}

1) Federation of Prefectural school Lunch Associations of Japan: School lunch. (in Japanese). http://www.zenkyuren. jp/lunch/ (Accessed September, 22, 2017)

2) Ministry of Education, Culture, Sports, Science and Technology, Japan: The Results of School Lunch Implementation Survey in 2015. (2017). (in Japanese). http:// www.mext.go.jp/b_menu/toukei/chousa05/kyuushoku/ kekka/k_detail/__icsFiles/afieldfile/2017/01/18/1381230_ 1_2_1.pdf (Accessed September, 22, 2017)

3) Sendai City Board of Education, Japan: About school Lunch Overview of school Lunch. (2017). (in Japanese), http://www.city.sendai.jp/kurashi/manabu/kyoiku/ inkai/kanren/kyushoku/ (Accessed September, 22, 2017)

4) Yamagata City Board of Education, Japan: School Lunch Center Comprehensive Information. (2017). (in Japanese). 
https://www.city.yamagata-yamagata.lg.jp/shimin/sub6/ kyusyoku/909elpd1118124826.html (Accessed September, 22, 2017)

5) Kyoto Prefecture Seika Town Board of Education, Japan: The 2nd Conference Recording 2013. (in Japanese). https://www.town.seika.kyoto.jp/cmsfiles/contents/ 0000013/13106/2502.pdf (Accessed September, 22, 2017)

6) Kobe City, Japan: Report of Municipal junior high school review meeting, Comparison of implementation systems of school lunches. (in Japanese). http://www.city. kobe.lg.jp/child/school/lunch/chusyoku/img/20120731 shiryou3.pdf (Accessed September, 22, 2017)

7) Ministry of Education, Culture, Sports, Science and Technology, Japan: The Results of School Lunch Implementation Survey in 2014. Lunch Implementation Status. (2015). (in Japanese). http://www.e-stat.go.jp/SG1/estat/ NewList.do?tid=000001016540 (Accessed September, 22, 2017)

8) Ministry of Education, Culture, Sports, Science and Technology: Annual Statistics 2017 School Number. (in Japanese). http://www.e-stat.go.jp/SG1/estat/List.do? bid $=000001015843 \&$ cycode $=0$ (Accessed September, 22, 2017)

9) Tsuchiura City, Japan: "School Lunch Renewal Basic Plan”. (in Japanese). http://www.city.tsuchiura.lg.jp/ data/doc/1384148258_doc_40_0.pdf (Accessed September, 22, 2017)

10) Osaka City, Japan: Press Release Presentation We will Implement a Model Project for Junior High School Lunches based on Small and Medium Parent-Child System. (in Japanese). http://www.city.osaka.lg.jp/hodoshiryo/ kyoiku/0000323941.html (From the month of 2017 via the National Diet Library Internet Data Collection Preservation Project) (Accessed September, 22, 2017)

11) Nagasaki Prefecture, Japan: School Lunch Guide, Chapter 5 School Lunch Operation and Management, Section 1 School Lunch Operation, I School Lunch Operation Organization. (in Japanese). https://www.pref.nagasaki.jp/ shared/uploads/2013/07/1374575247.pdf (Accessed September, 22, 2017)

12) Board of Education, Nagano Prefecture, Japan: School Lunch Guide, Operation and Management, 1 Operation and Organization of School Lunches. (in Japanese). http://www.pref.nagano.lg.jp/kyoiku/hokenko/hoken/ kyushoku/shokuiku/jokyo/documents/soshiki.pdf (Accessed September, 22, 2017)

13) Shizuoka Prefecture, Japan: Guidelines of School lunch program 2016. (in Japanese). http://www.pref.shizuoka. jp/kyouiku/kk-120/kyusyoku/kyuushokuguideline.html (Accessed September, 22, 2017)

14) Aichi Prefecture, Japan: "School Lunch Control and Guidance” (Seven Revised Edition) II School Lunch Operation Management. (in Japanese). http://www.pref. aichi.jp/uploaded/attachment/50987.pdf (Accessed September, 22, 2017)

15) Okayama Prefecture, Japan: School Health, Safety,
School Lunch Management Guide Chapter 4 School Lunch Management. (in Japanese). http://www.pref. okayama.jp/uploaded/life/343315_1688922_misc.pdf (Accessed September, 22, 2017)

16) Gunma Prefecture, Japan: School Lunch Guide, Chapter 1 Organization and Operation of School Lunches. (in Japanese). https://www.pref.gunma.jp/contents/000133596. pdf (Accessed September, 22, 2017)

17) Ministry of Internal Affairs and Communications: Local Autonomy List of Laws and Ordinances under the Jurisdiction of the Ministry of Internal Affairs and Communications Local Autonomy Law, Chapter 9, Section 3, Article 224. (in Japanese). http://law.e-gov.go.jp/htmldata/S22/ S22HO067.html (Accessed September, 22, 2017)

18) Ministry of Education, Culture, Sports, Science and Technology, Japan: School Lunch Act, Chapter 4 Miscellaneous Provisions (Burden of Expenses) Article 11. (in Japanese). http://law.e-gov.go.jp/htmldata/S29/S29HO 160.html (Accessed September, 22, 2017)

19) Ministry of Education, Culture, Sports, Science and Technology, Japan: The Results of School Lunch Implementation Survey 2006-2014. (in Japanese). http://www. e-stat.go.jp/SG1/estat/NewList.do?tid=000001016540 (Accessed September, 22, 2017)

20) Cabinet office, Japan: Response Text Information: November 24th, 2010 Cabinet Order Public Prosecutors 176, 159, 2010. (in Japanese). http://www.shugiin.go.jp/ internet/itdb_shitsumon.nsf/html/shitsumon/a176159. htm (Accessed September, 22, 2017)

21) Ministry of Education, Culture, Sports, Science and Technology: Summary Survey Results of Utilization of Local Products and Domestic Ingredients in School Lunch. (in Japanese). http://www.mext.go.jp/a_menu/ sports/syokuiku/1351896.htm (Accessed September, 22, 2017)

22) Ministry of Education, Culture, Sports, Science and Technology: Promotion of Education at School/Enrichment of School Lunch Guidance on Food Guidance - First Revised Edition - (March 2010) Chapter 4 Promotion of Education That Utilizes School Lunch as a Living Teaching Material. (in Japanese). http://www.mext.go.jp/ component/a_menu/education/detail/__icsFiles/afieldfile/ 2010/05/19/1292952_7.pdf (Accessed September, 22, 2017)

23) Ministry of Education, Culture, Sports, Science and Technology: School Lunch Sanitary Management Standards Partial Revision. (in Japanese). http://www.mext. go.jp/b_menu/hakusho/nc/t20030331003/t20030331003. html (Accessed September, 22, 2017)

24) Ministry of Education, Culture, Sports, Science and Technology: Survey on Cafeteria/Eating Utensils Usage in School Lunch: Summary of the Survey Results, 4. Study on Dining Room / Meal Equipment Usage Situation in School Lunch (as of May 1, 2006, Previous Survey 2003). (in Japanese). http://www.mext.go.jp/b_menu/toukei/ 001/kyusyoku/08011517/001.htm (Accessed September, 
22, 2017)

25) Ministry of Education, Culture, Sports, Science and Technology, Japan: The Results of School Lunch Implementation Survey in 2014. (2015). (in Japanese). http:// www.mext.go.jp/b_menu/toukei/chousa05/kyuushoku/ kekka/k_detail/1366273.htm (Accessed September, 22, 2017)

(Received September 22, 2017; Accepted June 5, 2018) 